\title{
Cryotherapy versus electrocautery in the treatment of genital warts
}

\author{
P D SIMMONS, F LANGLET, AND R N T THIN \\ From the Department of Genital Medicine, St Bartholomew's Hospital, London
}

SUMMARY Forty-two male patients with ano-genital warts were randomly allocated to a singleblind study of cryotherapy versus electrocautery. There was no significant difference in the success rates of these two forms of treatment in patients followed for three months. Cryotherapy was qualitatively much more acceptable to the patients than electrocautery. It seems particularly suited to patients with widely scattered warts who are unable to attend for regular treatment.

\section{Introduction}

Local applications of podophyllin in the treatment of genital warts give poor results.' ${ }^{\prime}$ Furthermore, patients have to either attend regularly for treatment or treat themselves at home. The former takes up much of their time while the latter may lead to enthusiastic over-treatment and produce chemical ulceration with attendant risks of phimosis or urethral stricture. Various forms of cautery have been advocated but few studies have been performed and follow up has been short. We have compared two forms of cautery in a single-blind study with a minimum period of surveillance of three months.

\section{Patients and methods}

Only men with ano-genital warts who had given informed consent were included in the trial. All patients were screened for other sexually transmitted diseases (STDs), which is routine practice in this clinic, ${ }^{1}$ and were treated if necessary. During and after treatment patients were advised to have sexual intercourse only when protected by a condom. Sexual partners were examined whenever possible. Patients were randomly allocated, by a random number table, to one of two treatments: (a) cryotherapy with nitrous oxide using a Spembly (Andover, Hants) series PCG 12R cryoprobe with no local anaesthetic, which produced ice-balls 1-2 mm larger than the diameter of the wart (no electrolyte or lubricant was used); and (b) electrocautery with $2 \%$ lignocaine as local anaesthetic. Patients were given

Address for reprints: Dr P D Simmons, Clinic 6, Leicester Royal Infirmary, Leicester LE1 5WW

Accepted for publication 12 December 1980 no other treatment for their warts and were advised to attend two weeks after their initial visit. They were then assessed by a second doctor who had no knowledge of the treatment given; he either recommended further treatment of the same type and review in a further two weeks or asked the patient to return at monthly intervals for three months if no warts were seen. Patients were offered an appointment in a wart clinic ${ }^{1}$ to encourage regular attendance.

STATISTICAL ANALYSIS

The $x^{2}$ test with Yates's correction was used.

\section{Results}

Twenty-four patients received cryotherapy and 18 patients electrocautery. The two groups of patients were comparable in their age range, country of origin, marital state, sexual orientation, previous sexually transmitted disease (including warts), and the numbers of warts present. The outcome of treatment was similar in both groups (table). Those patients receiving cryotherapy required a mean of $2 \cdot 6$ treatments whereas those receiving electrocautery required a mean of 1.4 treatments. These figures are statistically similar.

TABLE Comparison of results of treatment for genital warts using cryotherapy or electrocautery

\begin{tabular}{llll}
\hline Treatment & $\begin{array}{l}\text { No of } \\
\text { patients }\end{array}$ & $\begin{array}{l}\text { No followed } \\
\text { for 3 months* }\end{array}$ & $\begin{array}{l}\text { No cured at } \\
3 \text { monthst }\end{array}$ \\
\hline Cryotherapy & 24 & 16 & 10 \\
Electrocautery & 18 & 11 & 10 \\
\hline
\end{tabular}

* $\chi_{1}^{2} 0.0022 ; \mathrm{P}>0.05$

$+\chi_{1}^{2} 1.4599 ; \mathrm{P}>0.05$ 


\section{Discussion}

A method which will cure warts after only a few treatments is convenient for the patient and encouraging for the staff. The patient also quickly becomes non-infectious. Both forms of treatment removed warts after far fewer applications than are needed with podophyllin therapy. ${ }^{1}$

There have been several reports of the effect of cryotherapy on the management of ano-genital warts. Ghosh ${ }^{2}$ reported on 43 patients (male and female) followed for three months. Thirty-nine patients were clear of warts at this time. Some patients, however, underwent two freezing cycles of 45 seconds each, and all but one of these had severe local complications, which were often accompanied by acute pain. Balsdon ${ }^{3}$ treated 71 (male and female) patients; 49 of these needed three or fewer treatments but they were followed for only 4-6 weeks.

Injections of local anaesthetic are distressing to some patients, and if the warts are scattered several may be required. Although we did not attempt to quantify the patients' views on the treatment, cryotherapy was qualitatively much more acceptable. Having caused anxiety, discomfort, and even a little pain when injecting the local anaesthetic, the operator's natural desire is to apply enough electrocautery to minimise the need for further treatment. For this reason we decided on a two-week interval between treatment visits to allow the cautery-induced ulcers to heal. It is possible that cryotherapy would $\stackrel{\overparen{\mathbb{D}}}{\stackrel{\mathrm{C}}{-}}$ have been more effective if it had been used once $a \frac{\text { O }}{\omega}$ week. No ulceration occurred after cryotherapy and no patient needed local anaesthesia. In fact, no $\stackrel{\overrightarrow{\bar{S}}}{\overrightarrow{3}}$ patient in this series complained of pain.

Cryotherapy seems to be particularly suited to $\frac{}{0}$ patients with widely scattered warts who are unable $\frac{\overline{\bar{c}}}{\bar{s}}$ to attend for regular treatment. Electrocautery $\mathbb{\otimes}$ should probably be reserved for large solitary warts. Most departments have access to an electrocautery machine; special apparatus, however, is necessary for $\vec{\circ}$ cryotherapy, although many departments of $\overrightarrow{\vec{\omega}}$ gynaecology now have the equipment for minor procedures.

We are grateful to Dr R D Holt, Eastman Dental Hospital, London, for statistical advice, and to is Spembly Ltd, Andover, Hampshire, for the loan of $\omega$ the cryoprobe.

\section{References}

1. Simmons PD. A comparative double-blind study of $10 \%$ and $25 \%$ podophyllin in the treatment of ano-genital warts. $\mathrm{Br} J$ Vener Dis 1981;57:208-9.

2. Ghosh AK. Cryosurgery of genital warts in cases in which podophyllin treatment failed or was contraindicated. $\mathrm{Br} J$ Vener Dis 1977; 53:49-53.

3. Balsdon MJ. Cryosurgery of genital warts. $\mathrm{Br} J$ Vener Dis 1978;54:352-3. 